\title{
Gut microbiota, body weight and histopathological examinations in experimental infection by methicillin-resistant Staphylococcus aureus: antibiotic versus bacteriocin
}

\author{
K. Bendjeddou ${ }^{1}$, S. Hamma-Faradji ${ }^{1}$, A. Ait Meddour ${ }^{1}$, Y. Belguesmia ${ }^{2}$, B. Cudennec ${ }^{2}$, F. Bendali ${ }^{1}$, G. Daube $^{3}$, \\ B. Taminiau ${ }^{3}$ and D. Drider ${ }^{2 *}$ \\ ${ }^{1}$ Laboratoire de Microbiologie Appliquée, Faculté des Sciences de la Nature et de la Vie, Université de Bejaia, Bejaia 06000, \\ Algeria; ${ }^{2}$ BioEcoAgro $N^{\circ} 1158$, Univ. Lille, INRAE, Univ. Liège, UPJV, YNCREA, Univ. Artois, Univ. Littoral Côte d'Opale, ICV \\ - Institut Charles Viollette, 59000 Lille, France; ${ }^{3}$ Faculty of Veterinary Medicine, Department of Food Sciences - Microbiology, \\ FARAH, University of Liège, Quartier Vallée 2, Avenue de Cureghem 180, 4000 Liège, Belgium; djamel.drider@univ-lille.fr
}

Received: 2 August 2020 / Accepted: 23 November 2020

(c) 2021 Wageningen Academic Publishers

RESEARCH ARTICLE

\begin{abstract}
Bacteriocins have been steadily reported as potential agents that may contribute, in different ways, to overcome antimicrobial drug resistance. Here, holoxenic NMRI-F mice microbiota, their body weight recovery and histopathological alterations of organs like colon, spleen and liver were examined in mice intraperitoneally infected with $10^{8} \mathrm{cfu}$ of a clinical methicillin-resistant Staphylococcus aureus (MRSA-1), and treated with enterocin DD14 alone $(165 \mathrm{mg} / \mathrm{kg})$, erythromycin alone $(100 \mathrm{mg} / \mathrm{kg})$ or their combination. Animals that received both antimicrobials presented a better body weight recovery than other groups. Less pronounced histopathological alterations were observed in mice MRSA-infected and treated with bacteriocin than in those MRSA-infected but untreated or MRSAinfected and treated with erythromycin. Noteworthy, these alterations were absent when mice were treated with MRSA-infected and treated with both antibacterial agents. Furthermore, the genus richness was significantly lower in mice infected and treated with erythromycin, compared to mice infected and treated with both antimicrobials. The beta-diversity analysis showed that non-infected mice and those infected and treated with both antimicrobials, stand apart from the other groups as supported in a NMDS model. This in vivo study shows the relevance of bacteriocin, or bacteriocin-antibiotic formulation in protecting colonic, liver and spleen soft tissues and controlling the mouse gut microbiota, following MRSA infection.
\end{abstract}

Keywords: methicillin-resistant Staphylococcus aureus, enterocin DD14, erythromycin, histological sections, microbiota modifications

\section{Introduction}

The antimicrobial resistance (AMR) crisis is attributable, among other things, to massive use of antibiotics for human and animal health, and also to the drying up of the antibiotic discovery pipeline. By 2050 more people will die in the world because of AMR than any other illness according to different official sources (O'Neill, 2016). AMR involving methicillin-resistant Staphylococcus aureus (MRSA) have been reported in the hospital environment as being responsible for a high number of deaths (Dumitrescu et al., 2010; Köck et al., 2010). MRSA is a successful modern pathogen, living as a commensal and transmitted in both health-care and community settings. This harmful pathogen is a leading cause of clinical conditions, such as bacteraemia, endocarditis, skin and soft tissue infections, bone and joint infections and various hospital-acquired infections. This pathogen is still posing serious clinical menace, with high morbidity and mortality rates (Turner et al., 2019). Treatment options for MRSA are limited and several antimicrobials are under development, including vaccination as preventive measure (Lee et al., 2018). Of note, MRSA has become a therapeutic challenge, even though antibiotics like teixobactin, with a distinct mode of action from methicillin, exist (Ling et al., 2015). Discovery and development of new antibiotics has not been of high 
priority during the last decades, which could be partially explained by lack of investment incentive due to continuing lack of success.

To help curb AMR, new antibiotics and other therapeutic options are needed. Antimicrobial peptides (AMPs) stand as key alternatives to fading antibiotics and could rekindle the drying pipeline. AMPs possess similar, or even better effective activity profiles than traditional antibiotics (Seo et al., 2012), in spite their sensibility to proteolytic and gastric degradation (Renukuntla et al., 2013). The World Health Organization is presently calling for a groundbreaking action to avert this AMR crisis. International agencies and experts are also calling for immediate and coordinated action to tackle AMR. In this perspective, the global action encourages not only research of new antibiotics, in spite of industry recalcitrance, but also fosters implementation of key alternatives like phage therapy, faecal transplantation and antimicrobial peptides.

AMPs are produced by all living cells, as part of their innate immune system (Mishra et al., 2017), and do play a role in the protection of the host-cells against invading pathogens (Spencer et al., 2014). AMPs are endowed with intrinsic antibiotic activities, and are foreseen to replace fading or help improving their activities through synergistic interactions (Lei et al., 2019). Bacteriocins are ribosomally synthesised by both Gram-negative and Gram-positive bacteria (Drider and Rebuffat, 2011), as well as Archea (Kumar and Tiwari, 2017). Applications of bacteriocins, mainly those produced by lactic acid bacteria (LABbacteriocins), were limited to the food industry as food preservatives (Chen and Hoover, 2003; O'Connor et al., 2020), and the lantibiotic nisin is presently the only LABbacteriocin to be qualified by the FDA (US Food, Drug and Administration) as food-preservative E234. The last decades has witnessed a steadily increasing number of studies dedicated to the potential use of LAB-bacteriocins as therapeutics. Indeed, these molecules are gaining more and more interest, and their momentum to treat multidrug species, in humans and animals is increasing day by day (Cotter et al., 2013; Meade et al., 2020; Vieco-Saiz et al., 2019).

Recently, we established the capabilities of the bacteriocins enterocin 28 (DD28), and enterocin 93 (DD93) to potentiate the in vitro activity of erythromycin against a MRSA-1 strain (Al Atya et al., 2016). Interestingly, this synergistic interaction was also observed for enterocin 14 (DD14), when added to erythromycin. Of importance, the DNA sequences of EntDD14, EntDD28 and EntDD93 were identical (unpublished data). Of note, further studies were performed only on EntDD14, namely, genome sequencing and analysis (Belguesmia et al., 2017), and also by identification of the peptide amino acid sequence of this bacteriocin (Caly et al., 2017). These studies collectively enabled us to classify EntDD14, as a leaderless class IIb bacteriocin. To extend our knowledge on the potential use of this in vitro synergistic bacteriocin-antibiotic interaction against the MRSA-1 strain, we looked at the effects of EntDD14-erythromycin combination in vivo using mice models. To that purpose, the NMRI-F mice were examined for the body weight recovery; microbiota stability and histological alterations of the intestine; spleen and liver; after their MRSA-infection and treatment with antibiotic (erythromycin), bacteriocin (EntDD14) or their combination.

\section{Materials and methods}

\section{EntDD14 preparation and antibiotic activity}

The bacteriocinogenic Enterococcus faecalis 14 was grown overnight at $37^{\circ} \mathrm{C}$, in Brain Heart Infusion (BHI) broth (Fluka Analytical, Steinheim, Germany). Then, the culture was centrifuged $\left(8,000 \times g, 4{ }^{\circ} \mathrm{C}, 10 \mathrm{~min}\right) .40 \mathrm{ml}$ of the resulting cell-free supernatant (CFS) were passed, at room temperature $\left(20-25^{\circ} \mathrm{C}\right)$ with a flow rate of $1 \mathrm{ml} / \mathrm{min}$, through a $\mathrm{C}_{18}$ solid phase extraction (SPE) cartridge containing octadecyl silica as a filler to retain non-polar compounds by strong hydrophobic interaction (Agilent, Santa Clara, CA, USA). Several washing steps with $40 \mathrm{ml}$ of eluents containing successively 10, 20, 30 and 40\% (v/v) of acetonitrile, mixed with deionised water, permitted the removal of contaminants. The semi-purified EntDD14 was eluted with $50 \%(\mathrm{v} / \mathrm{v})$ of acetonitrile. This active fraction was dried using a SpeedVac and resuspended in ultrapure water. The DD14 concentration was determined by the Bradford protein assay (Bradford, 1976), whereas its total activity was assessed as described by Dabard et al. (2001). Then, and according to the protocol described by Al Atya et al. (2016), the minimal inhibitory concentrations (MICs) of EntDD14 or erythromycin (Ery) were determined as well as their fractional inhibitory concentration index (FICI) to assess their interaction.

\section{Animal design, diet and housing conditions}

Holoxenic NMRI-F (Naval Medical Research Institute) strain of mice were obtained from the Pasteur Institute of Algiers (Algeria). Thus, 35 female mice (NMRI-F), with a weight of $30 \mathrm{~g}$ were randomly assigned to 5 different groups (G1, G2, G3, G4 and G5). They were housed individually in metal cages under controlled room temperature $\left(20 \pm 2{ }^{\circ} \mathrm{C}\right)$, humidity $(50 \pm 5 \%)$, constant $12 \mathrm{~h} / 12 \mathrm{~h}$ light/dark cycle and fed with mouse diet obtained from a local company (ONAB, Bejaia, Algeria), and water for 1 week ad libitum before the experimental analysis and monitoring. 


\section{Challenge tests}

The antibacterial agents, namely erythromycin and EntDD14, were dissolved in $0.9 \%(\mathrm{v} / \mathrm{v})$ saline sterile water. The animals were divided in five groups (G1 to G5). G1 was used as control, the other four groups were challenged intraperitoneally (right side) with $100 \mu \mathrm{l}$ of MRSA-1 strain at $10^{9} \mathrm{cfu} / \mathrm{ml}$. Then, $1 \mathrm{~h}$ later, all groups, except $\mathrm{G} 2$, received a single dose of a solution of $100 \mu \mathrm{l}$ of erythromycin at $100 \mathrm{mg} / \mathrm{kg}$ (G3), or EntDD14 at $165 \mathrm{mg} / \mathrm{kg}$ (G5) or of both of them (G4) (left-side). Following these challenge tests and administration of the antibacterial agents abovecited, animals were regularly examined for adverse effects and morbidity during $96 \mathrm{~h}$. Their body weights were daily registered. At the end of the $96 \mathrm{~h}$ of experimental monitoring, 5 different samples of faeces from each group were randomly taken for DNA extraction and microbiota analyses.

\section{Ethical procedure}

Animals were sacrificed and one animal per group was used for histological examinations following eosin-staining of organs, such as colon, liver and spleen. All international and national applicable guidelines were scrupulously respected for animal care and welfare.

\section{Histological sections examinations}

Following animal euthanasia and dissection, liver, spleen and colon were removed and immediately put into $10 \%$ $(\mathrm{v} / \mathrm{v})$ of neutral-buffered formalin solution. The histological sections were prepared at a private laboratory of anatomy, cytology and pathology (Bejaia, Algeria). The inclusion of the sections was carried out as previously reported (Lussier, 1989), and the staining of the slides was performed using the haematoxylin-eosin procedure (Sobotta and Welsch, 2000).

\section{DNA extraction and purification}

Total bacterial DNA was extracted from $25 \mathrm{mg}$ of faeces using a QIAamp PowerFecal extraction kit (Qiagen, Venlo, the Netherlands), according to the manufacturer's recommendations. A first mechanical lysis step of $5 \mathrm{~min}$ using lysing matrix E tubes (MP Biomedicals, Illkirch, France) and extraction kit lysis buffer was applied. The DNA was then diluted with DNAse and RNAse-free water and its concentration and purity were evaluated by optical density at 260/280 nm using a Nano Drop ND-1000 spectrophotometer (Isogen, St-Pieters-Leeuw, Belgium). Then, DNA samples were stored at $-20^{\circ} \mathrm{C}$ until they were used for the sequencing analysis.

\section{S rDNA high throughput amplicon sequencing}

PCR-amplification of the $\mathrm{V} 1-\mathrm{V} 3$ region of the $16 \mathrm{~S}$ rDNA, and library preparation were performed with the following primers (with Illumina overhand adapters), forward (5'-GAGAGTTTGATYMTGGCTCAG-3'), and reverse (5'-ACCGCGGCTGCTGGCAC-3'). Each PCR product was purified with the Agencourt AMPure XP beads kit (Beckman Coulter, Pasadena, CA, USA) and submitted to a second PCR round for indexing, using the Nextera XT index primers 1 and 2. After purification, PCR products were quantified using the Quant-IT PicoGreen (ThermoFisher Scientific, Waltham, MA, USA) and diluted to $10 \mathrm{ng} / \mu \mathrm{l}$. A final quantification, by qPCR, of each sample in the library was performed using the KAPA SYBR $^{\circ}$ FAST qPCR Kit (KapaBiosystems, Wilmington, MA, USA) before normalisation, pooling and sequencing on a MiSeq sequencer using v3 reagents (Illumina, San Diego, CA, USA). Positive control using DNA from 20 defined bacterial species and a negative control (from the PCR step) were included in the sequencing run. Raw amplicon sequencing libraries were submitted to the NCBI database under bioproject number PRJNA623490.

\section{Sequence analysis and $16 S$ rDNA profiling}

Sequence reads processing was performed as previously described using MOTHUR software package v141.1 (Schloss et al., 2009) and VSEARCH algorithm for chimera detection (Rognes et al., 2016). A clustering distance of 0.03 was used for operational taxonomic unit (OTU) generation. $16 \mathrm{~S}$ rDNA reference alignment and taxonomical assignment were based upon the SILVA database (v1.32) of full-length 16S rDNA sequences (Quast et al., 2013).

\section{Data analysis}

Subsample datasets were obtained and used to evaluate ecological indicators (Goods Coverage, Chao richness index and reciprocal Simpson microbial diversity of the samples) and beta-diversity (using a distance Bray-Curtis dissimilarity matrix) using MOTHUR. Beta-diversity was visualised with a Bray-Curtis dissimilarity matrix based non-parametric dimensional Scaling (NMDS) model using vegan (Oksanen et al., 2019) and vegan3d (Oksanen et al., 2018) packages on R. Sample clustering and beta-dispersion were respectively assessed on Bray-Curtis dissimilarity matrix with AMOVA and HOMOVA tests using MOTHUR (using 10,000 iterations on the rarefied table).

\section{Statistical analysis}

All results were expressed as mean \pm standard deviation. Statistical analysis, except for microbiota and mouse bodyweight analyses, was performed using the one-way analysis of variance (ANOVA) procedure of Statistica 
5.5 (1999 edition) software (Statsoft, Tulsa, OK, USA). Differences among means were detected by paired Student's test. Values of $P<0.05$ were considered statistically significant. Statistical analysis of mouse body weights was conducted in GraphPad prism v6.1 (La Jolla, CA, USA), one way ANOVA was applied with Tukey's test for post comparison $(P<0.05)$. Microbial population structure and microbial population abundance difference between groups were assessed with the Kruskal-Wallis non parametric test followed by paired-tests corrected by Benjamini, Krieger, Yekutieli False Discovery Rate using PRISM 7 (Graphpad Software), differences were considered significant for a q-value $<0.01$.

\section{Results}

\section{EntDD14 and erythromycin enabled synergistic interaction in vitro against MRSA-1}

MRSA-1 strain was resistant to erythromycin (MIC $16 \mu \mathrm{g} /$ $\mathrm{ml}$ ) according to the CA-SFM guideline (CA-SFM, 2019). Of note, the MIC of erythromycin decreased from 16 to $1 \mu \mathrm{g} / \mathrm{ml}$, in the presence of EntDD14, arguing a potential synergistic interaction. Indeed, this interaction was confirmed by the FIC value 0.313 . Antibacterial activities of EntDD14, erythromycin and their combination are given in Table 1. Interpretation of these data were performed as reported by Petersen et al. (2006).

\section{Animals infected with MRSA-1 and treated with erythromycin + DD14 show a better body weight recovery than groups G2, G3 and G5}

Results showed that the mouse body weights were not significantly different between groups during the first three days of the experiment but at day 4 all the treatments led to a significant body weight decrease when compared to G1
(Supplementary Figure S1). However, the mice for which EntDD14 and erythromycin were administrated, alone (G5) or in association (G4), presented a significantly higher body weight than mice from G2. Moreover, the mice treated by both EntDD14 + erythromycin (G4) appeared to be less affected than other mice treated with either drug alone. The $P$-values obtained were 0.0688 (G4 versus G5), and 0.0375 (G4 versus G5).

\section{Histopathological examination revealed severe alterations in $\mathbf{G} 2$ and $\mathbf{G} 3$ mice}

The histological sections were analysed for the main organs, namely colon, spleen and liver. These examinations revealed G1 presented a preserved colic architecture with normal height crypts and devoid of any inflammatory and/or ulcerated signs (Figure 1 - IA). Nevertheless, intraperitoneal administration of MRSA-1 strain to mice caused villous atrophy, and other adverse effects like infectious and inflammatory symptoms, outlined by a mesenteric lymphadenopathy and ileal intestinal mucosa, respectively (Figure 1 - IB). These adverse effects were also observed for animal infected with MRSA-1 strain and treated with erythromycin (Figure $1-\mathrm{IC}$ ). Architecture of crypts was mostly impaired, and inflammatory signs with lymphocytic infiltration were observed (Figure 1 - IC). Of note animals challenged with MRSA-1 strain and treated with EntDD14 exhibited less pronouncedly these adverse effects, as indicated on Figure 1 - IE. Importantly, when mice were challenged with MRSA-1 and concomitantly treated with both antibacterial agents, EntDD14+Erythromycin, a normal anatomy was observed. This normality, as seen on Figure 1 - ID, is associated with normal intestinal mucosa and intact villosities. This anatomy and cellular architecture are fairly equivalent to those from the animal group used as positive control. Despite that the MRSA-1 strain is resistant to erythromycin, and EntDD14 weakly

Table 1. Minimum inhibitory concentrations (MICs) of antimicrobials and their association against methicillin-resistant Staphylococcus aureus (MRSA)-S1.,2,3

\begin{tabular}{|c|c|c|c|c|c|c|}
\hline Strain & DD14 ( $\mu \mathrm{g} / \mathrm{ml})$ & Ery ( $\mu \mathrm{g} / \mathrm{ml})$ & DD14-Ery ( $\mu \mathrm{g} / \mathrm{ml})$ & $\mathrm{FIC}_{\mathrm{DD} 14}{ }^{4}$ & $\mathrm{FIC}_{\text {Ery }}{ }^{5}$ & $\mathrm{FICl}^{6}$ \\
\hline MRSA-S1 & 154 & 16 & $38.5 / 1$ & 0.25 & 0.063 & 0.313 \\
\hline $\begin{array}{l}{ }^{1} \text { Minimum i } \\
\text { after overnic } \\
{ }^{2} \mathrm{FIC} \text { index } \\
\text { association, } \\
{ }^{3} \mathrm{DD} 14=\mathrm{er} \\
{ }^{4} \mathrm{FIC} \mathrm{CD}_{\mathrm{DD}}= \\
{ }^{5} \mathrm{FIC} \text { Ery }=\mathrm{N} \\
{ }^{6} \mathrm{FICl}=\mathrm{FIC}\end{array}$ & $\begin{array}{l}\text { oncentrations (MI } \\
\text { tion. } \\
\text { f DD14 in associ } \\
\text { et al. (2006) defi } \\
\text { D14; Ery = erythr } \\
\text { D14 in associatio } \\
\text { in association/MI } \\
\text { Ery. }\end{array}$ & $\begin{array}{l}\text { are defined as th } \\
\text { /MIC of DD14 } \\
\text { synergy as } \sum F \\
\text { cin; FIC = fracti } \\
\text { of DD14 alon } \\
\text { Ery alone. }\end{array}$ & $\begin{array}{l}\text { est concentration of an } \\
+ \text { (MIC of erythromy } \\
\text {, additivity as } 0.5<\sum \\
\text { hibitory concentration }\end{array}$ & $\begin{array}{l}\text { cin in asso } \\
F \mid C \leq 1 \text {, indiff } \\
; F I C I=\text { frac }\end{array}$ & $\begin{array}{l}\text { C of eryth } \\
1<\sum \mathrm{FIC} \\
\text { bitory cono }\end{array}$ & $\begin{array}{l}\text { th of a microorganism } \\
\text { one). In antimicrobial } \\
\text { agonism as } \sum \mathrm{FIC}>4 \text {. } \\
\text { dex. }\end{array}$ \\
\hline
\end{tabular}


A

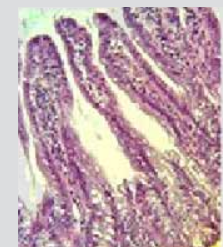

Basting
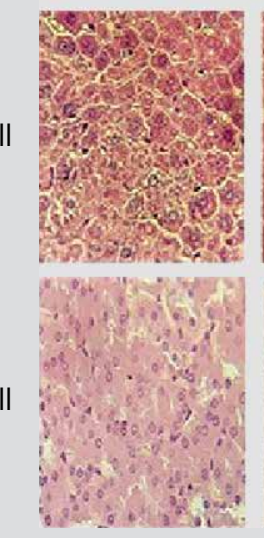

$-$
B
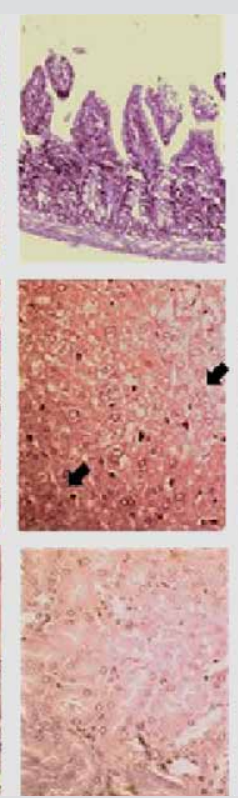

$+$

$-$
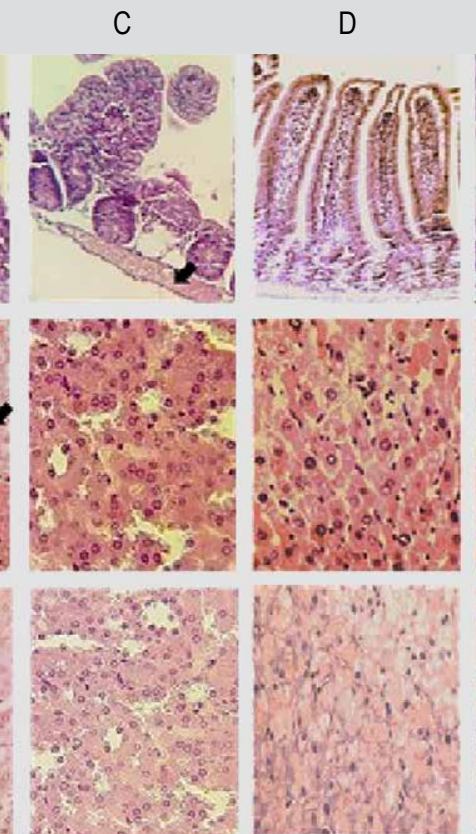

$+$

$+$

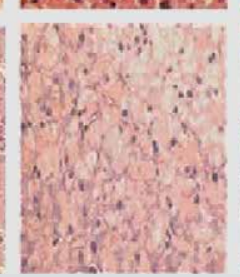

$+$

$+$
$E$
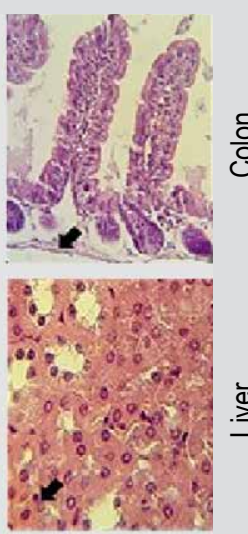

$\stackrel{\bar{\Phi}}{\underline{\perp}}$

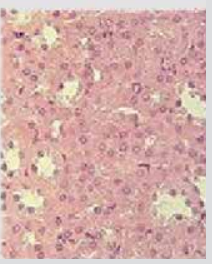

$+\quad$ MRSA-S1

- $\quad$ Erythromicin

$+\quad$ DD14

Figure 1. Histological examination and eosin-stained sections of organs: colon (I), liver (II) and spleen (III). Tissues were from mice G1 (A) (-, -, -), G2 (B) (+, -, -), G3 (C) (+, +, -), G4, (D) (+, +, +) and G5 (E) $(+,-,+)$. Organs are indicated on the right side of the picture. Arrows indicate lymphocytes infiltrating, binucleation and granulo-vitreous degeneration.

active, their association enabled synergistic interaction in vitro (Table 1). These results convey the potency and utility of such combination in fighting staphylococcal infections.

The histological sections of liver were studied similarly. As depicted on Figure 1 - IIA, the animal from the control group presented a well conserved cellular architecture, which is typically present in intact organ. Nevertheless, this architecture was affected when mice were intraperitoneally challenged with the MRSA-1 strain. Indeed, symptoms of liver injury were marked by several adverse events such as haemorrhage, increase in both cytoplasm density, and chromatin content, binucleation process, centrolobular hepatic necrosis and inflammatory reactions (Figure $1-$ IIB). Of note, centrolobular hepatic necrosis was markedly associated with congested veins, while inflammatory reaction was, in turns, associated with hepatocyte degeneration (Figure 1 - IIB). The histological analysis revealed overall similar adverse effects in mice infected with the MRSA-1 strain and treated with erythromycin (Figure 1 - IIC). Accordingly, necrosis was noticeably represented by the disappearance of caniculi and loss of the zone of drainage, whereas cellular intoxication was marked by loss of polygonal and radial hepatic cell shapes, cell junctions/ ends as well as bi-nucleation process in the nucleus, and increased chromatin concentration (Figure 1 - IIC).
These lesions were less pronounced in mice infected with MRSA-1 strain and treated with EntDD14 alone (Figure 1 - IIE). Nevertheless, mice infected with MRSA-1 strain and treated by EntDD14+erythromycin were less afflicted since signs of necrosis were insignificant, as noted with a faint vascular congestion, and increase in the nuclear chromatin concentration (Figure 1 - IID). Mice from group 1 were used as baseline control, since they had received no antibacterial agent and/or MRSA-1 strain. Histological sections of spleen from an animal taken from this group were normal, with well-organised cellular architecture and typically healthy spleen cells (Figure 1 - IIIA). Similar to other organs, challenge and treatment caused modifications, which were treatment-dependent. Signs of severe adverse effects, supporting a vascular affection, were observed in mouse of G2. These signs included manifest venous congestion of sinusoids, and haemorrhagic suffusion. In addition, infection and inflammatory reactions were observed. They showed on one hand a myeloid metaplasia and abundance of megakaryocytes, and on the other hand granulo-vitreous degeneration (Figure 1 - IIIB). However, when mice came from groups challenged with MRSA1 and receiving erythromycin or EntDD14, only signs of bacterial infection characterised by a splenomegaly were noticeably observed (Figure 1 - IIIC and IIID). The histological analyses did not show, at the cellular level, clear 
differences with that of the group I (Figure 1 - IIIA, IIIC and IIIE). Nonetheless, the spleen tissues of mice infected with MRSA-1 strain and treated with both antibacterial agents, EntDD14+Erythromycin, displayed similar organisation to those of the animal from group 1, that was used as control baseline (Figure 1 - IIID).

\section{Analysis of faecal microbiota}

From the 25 libraries, we obtained 3,204,042 raw reads and 1,690,250 reads after cleaning and chimera detection (median length of $503 \mathrm{bp}$ ). We retained a subsampled pool of 10,000 reads per sample to proceed with OTU binning (0.03 cut-off) for a total of 5,945 OTUs. Mean sampling Good's coverage was $99.87 \%$, with no statistical difference between groups. Notably, the faecal microbial population structure was assessed at the genus level. Intrinsic diversity analysis revealed that genus richness was significantly lower in G2, compared to mice from G1 and G4 (Supplementary Figure S2A). Beta-diversity analysis showed that G1, and G4, stand apart from the other groups as illustrated in a NMDS model ( $K=3$, stress 0.04) (Supplementary Figure $\mathrm{S} 2 \mathrm{~B})$. This clustering, however, is only significant for G1 versus G2 (AMOVA test, $P=0.00396)$. Moreover G4 versus G2 does not reach significance but is close $(P=0.00689)$.

The alpha biodiversity index Shannon is a continuous variable with a lower bound of zero and no upper bound. Higher is the value, greater is the diversity. As seen in Supplementary Figure S2A, the level of diversity declined following the infection with MRSA-1 strain, and the Shannon's index declined significantly compared to the control. However, the diversity was partly recovered after administration of any drug alone, raising the biodiversity at the same level. However, the noticeable effect was obtained when these drugs were administered concomitantly. The Shannon index increased, reflecting an enhancement of the richness at the genus level.

Supplementary Figure S3 indicates that Bacteroidetes and Firmicutes are the prevailing phyla as expected for faecal microbiota. At the genus level, the main genera in G1, G2, G3 and G5 belong to the Firmicutes with Lactobacillus, Enterococcus and Turicibacter being present. However, in G1 and G4, the most abundant population belong to the Bacteroidetes with Alistipes genus and population belonging to the Prevotellaceae and Muribaculaceae families. Moreover, Kruskal-Wallis $\mathrm{H}$ test evaluation for the population abundance in the different groups was performed and highlighted several populations of interest (Supplementary Table S1). Mainly we confirmed the shift Firmicutes/Bacteroidetes between G1 and G2 (q<0.0001) but also between G4 and the other infected groups G2, G3 and G5 $(\mathrm{q}<0.0001)$. These differences can also be found at the genus level with Lactobacillus being significantly more abundant in G2, G3 and G5 compared to G1 and G4. The
Enterococcus population is also more abundant in G3 and G5 compared to the others.

\section{Discussion}

To bolster antibiotic stewardship initiatives, the LABbacteriocins are gaining more and more interest for therapeutic applications (Dischinger et al., 2014; Meade et al., 2020; Ołdak and Zielińska, 2017). With respect to this objective, we provide in the present study original data on the in vivo cytotoxicity of class IIb enterocin DD14 (Belguesmia et al., 2017; Caly et al., 2017), and studied its impact on different markers as discussed below. Overall, studies dedicated to cytotoxicity and immunotoxicity of bacteriocins are very limited, in spite of the relevance of this aspect to food or medical applications. Nisin, which is the only authorised and marketed bacteriocin used as a food additive (E234), is the most studied model for cytotoxicity aspects.

The effects of EntDD14, erythromycin, or their association were examined in vivo using the NMRI-F mice, as murine model. These effects concerned markers such as body weight change, gut microbiota stability and histopathological lesions in the NMRI-F mice, challenged with a clinical MRSA-1 strain, and treated with EntDD14, erythromycin, or both. To clarify the use of these molecules, we suggest referring to our recently reported in vitro data, in which we showed that DD28 and DD93 were able to potentiate erythromycin against the target MRSA-1 strain (Al Atya et al., 2016). Importantly, the DNA sequences of EntDD14, EntDD28 and EntDD93 are fully identical (unpublished data), despite producing strains having been isolated from different samples (Al Atya et al., 2016; Caly et al., 2017). Of note, the EnDD14 was the first one which was fully characterised (Caly et al., 2017). In addition, all these bacteriocins are weakly active against the MRSA-1 strain. Nevertheless, when added to erythromycin, any of these bacteriocins provides in vitro synergistic interactions against the MRSA-1 strain (Al Atya et al., 2016) (Table 1). Here, we examined the effects of EntDD14, erythromycin, or both, when administered intraperitoneally to NMRI-F mice concomitantly infected with the MRSA-1 strain. The route of administration of bacteriocins is a key element. Oral administration can be counterproductive because of conditions met during the gastrointestinal transit, such as low $\mathrm{pH}$, proteases, etc. These conditions are unfavourable to bacteriocins, and can impair their activity and stability (Fernandez et al., 2013). For example, Kheadr et al. (2010) outlined the instability of pediocin PA-1/AcH in the dynamic in vitro TIM model, which mimics the upper human gastrointestinal tract.

Nevertheless, the oral administration of bacteriocins can gain insight into their safety aspects. Thus, Frazer et al. (1962) administered orally nisin to rats and proclaimed the 
safety of this bacteriocin. However, de Almeida Vaucher et al. (2011) reported histopathological alterations of spleen, skin and liver following oral nisaplin administration to mice. On the other hand, Sahoo et al. (2017) showed that mice receiving orally and daily $0.5 \mathrm{mg} / \mathrm{kg}$ of bacteriocin TSU4 for 21 days, showed no deaths, and were devoid of any immunogenicity or toxic effect.

Furthermore, the class IIc enterocin AS 48 was intraperitoneally administered to BALB/c mice and the authors reported (Baños et al., 2019) moderate vacuolar degeneration in the hepatocytes, conversely to mice fed with nisin. However, Ketaren, et al. (2016) showed that mice receiving intraperitoneally high amounts of pediocin N6 (up to $20,000 \mathrm{mg} / \mathrm{kg}$ ) did not show any sign of acute toxicity.

In the present study, EntDD14 was administrated intraperitoneally to NMRI-F mice, to avoid proteolytic and gastric degradation of EntDD14. Additionally, this route was also used for administration of erythromycin, and challenge with the MRSA-1 strain to allow its rapid spread into the bloodstream. As reviewed by Turner et al. (2019), Staphylococcus aureus expresses different virulence factors, such as toxins, immune-evasive surface factors and enzymes that promote its tissue invasion. Other harmful toxins like exfoliative toxins, adhesins and haemolysins were reported (Malachowa and DeLeo, 2010). These authors revealed that some MRSA strains can utilise bacteriocins as MGE (mobile-genetic-elements) to inhibit competing or commensal bacteria (Malachowa and DeLeo, 2010). In the present study, no death was registered during 4 days of experimental analysis and monitoring, in spite of a dose of pathogen administrated to the mice. This can be explained by different factors, such as strain adaptation, genetic reorganisation and finally loss of the virulence traits (Mizobuchi et al., 1994).

In terms of the body weight incremental, we noticed at the end of 4 days experimental analysis that the mice from G4 were less affected than those from other infected groups G2, G3 and G5. Examination of histological sections revealed severe histopathological damage in the colon, spleen and liver from the mice of G2 and G3. These symptoms and signs of necrosis, cellular toxicity and inflammation observed in G2 and G3 can be attributed to many factors including toxins secreted locally by MRSA-1 and their dissemination via the blood circulation. In MRSA-infected mice treated with erythromycin alone (G3), these adverse effects were expected because this strain is resistant to this antibiotic (Al Atya et al., 2016) (Table 1). Erythromycin is used for treatment of nosocomial infections mostly caused by $S$. aureus, but because surviving bacteria are frequently found most patients are recommended to receive combination therapy of erythromycin with other agents active against $S$. aureus. Erythromycin is suitable for treating Gram-positive infections in humans. By increasing the concentration of erythromycin to $600 \mathrm{mg} / \mathrm{g}$ of faeces, its spectrum has been shown to be extended and became active against some intestinal Gram-negative bacteria such as those from Enterobactericeae family (Hartley et al., 1978). The histopathological alterations reported in mice from G2 and G3 persisted, but to a lesser extent to the animals in G5, which had been infected and EntDD14 treated. Finally, these clinical signs were cleared following treatment of infected mice with erythromycin+ EntDD14. The cationic nature of LAB-bacteriocins can prejudice their effectiveness, because they can bind to blood components (Ghobrial et al., 2010). Data gathered here indicate the absence of toxicity of EntDD14, and revealed that erythromycin+EntDD14 is a suitable association that provides protection from deleterious effects of MRSA.

With respect to the microbiota aspects, it should be remembered that although antibiotics are invaluable weapons for eliminating malevolent pathogens, they can also induce long-lasting deleterious effects on the host such as the destabilisation of the microbiota, leading to dysbiosis (Lagier et al., 2012; Lange et al., 2016). The impact of antibiotics on the gut microbiota depends on its route of administration, dose and time of administration (Ruppé et al., 2018). Thus, we looked at the impacts of erythromycin, EntDD14, or their association on the NMRI-F mouse gut microbiota under different experimental conditions. Firstly, we looked at the phyla composition in each mouse group. The Firmicutes/Bacteroidetes ratio (F/B) is a key factor in mouse obesity (Ley et al., 2005), and this is also consistently confirmed for humans (Barlow et al., 2015; Sweeney and Morton, 2013).

Metagenomic analyses of the faecal samples from G1 revealed, amongst other phyla, Epsilonbacteteraeota, Lentisphaerae and Proteobacteria. Epsilonbacteteraeota phylum has been introduced into the bacterial taxonomy, following re-classification of class Epsilonproteobacteria (Waite et al., 2017), whereas the Lentisphaerae phylum, has been included in the PVC super-phylum, which initially contained three phyla Planctomycetes, Verrucomicrobia and Chlamydiae (Fuerst, 2013). In the present study, a shift in the gut faecal composition occurred following infection of mice with MRSA-1strain (G2), and their subsequent treatment with erythromycin (G3), or EntDD14 (G5).

The Proteobacteria phylum has been reported to be associated with obesity complex disease (Bai et al., 2019; Rizzatti et al., 2017). Proteobacteria, qualified as key dysbiosis players, are not only present in the gut and stools but also in others human body sites, like skin, oral cavity, tongue or vaginal tract (Huttenhower et al., 2012). This phylum also contains pathogens such as Brucella, Rickettsia, Bordetella, Neisseria, Escherichia, Shigella, Salmonella, Yersinia, and Helicobacter, which are associated with both intestinal and extra-intestinal diseases (Langgartner et al., 
2017; Maharshak et al., 2013). The metagenomic analyses performed here showed that faecal samples from mice of G4 contained more Bacteriodetes than Firmicutes. This is an important point because mice from G4 exhibited greater body weight recovery profiles (Supplementary Figure S1), and earlier studies reported a predominance of Bacteroidetes in overweight and obese individuals (Schwiertz et al., 2010), and a positive correlation between the faecal concentrations of Bacteroides and the body mass index (Ignacio et al., 2016). Deeper analyses of these metagenomic data revealed a relative abundance of Helicobacter, Lachnospiraceae, Bacteroidales/Bacteroides, Prevotellaceae and Muribaculaceae. Interestingly, Muribacaculaceae is known to be the dominant bacterial group in the mouse gut (Seedorf et al., 2014). Nevertheless, this profile has been modified in other groups (G2, G3, G4 and G5), being noteworthy the relative abundance of probiotic genera, such as Lactobacillus and Enterococcus in G3 and G5.

\section{Conclusions}

During this study we established that Holoxenic NMRI-F mice infected with the MRSA-1 strain, and treated with erythromycin, EntDD14 or both of them, responded differently based on the clinical parameters used. Interestingly the MRSA-infected mice concomitantly treated with erythromycin and EntDD14 showed the best body weight recovery. Of note, this bacteriocin-antibiotic combination enabled protection of the soft tissue of organs such as colon, liver and spleen, against the MRSA1 strain. Moreover the faecal microbiota composition, and more particularly the beta-diversity analysis revealed a convergence between the uninfected mice and those treated with MRSA-infected and treated concomitantly with bacteriocin-antibiotic. These new advances constitute a new step in the valorisation of LAB-bacteriocins as therapeutic agents. This unique study carried out in vivo on the Holoxenic mice models permitted to show the clinical and metagenomic alterations following mice infection with MRS-1 strain and their treatment with erythromycin, EntDD14 and both of them. To strengthen this approach, further clinical investigations using other molecules and infection models will be tested in the near future.

\section{Supplementary material}

Supplementary material can be found online at https://doi. org/10.3920/BM2020.0155.

Table S1. Abundance of bacterial taxa expressed in percentage that are statistically impacted by the MRSA challenge or the post-challenge treatment, as determined by $16 \mathrm{~S}$ amplicon sequencing.
Figure S1. Body weight evolution during animal experimentation and monitoring.

Figure S2. Intrinsic bacterial genus diversity, genus richness and evenness deduced respectively from reciprocal Simpson Index, Chao1 index and Simpson index (A). Non-metric dimensional scaling model with three axis of the five mouse groups (B).

Figure S3. Changes in microbial populations in the faecal content, assessed by $16 \mathrm{~S}$ profiling.

\section{Acknowledgements}

The authors would like to thank la Région des Hauts-deFrance for supporting part of this work, through CPER/ FEDER Alibiotech (2016/2021). The authors are indebted to Dr. Steve W Elson, Dr. Bruce Seal (Oregon State University) and Prof. Luis A Nero (Universidade Federal de Viçosa, Brazil) for critical reading of the manuscript.

\section{Conflict of interest}

The authors declare no competing interest

\section{References}

Al Atya, A.K., Belguesmia, Y., Chataigne, G., Ravallec, R., Vachée, A., Szunerits, S., Boukherroub, R. and Drider, D., 2016. Anti-MRSA activities of enterocins DD28 and DD93 and evidences on their role in the inhibition of biofilm formation. Frontiers in Microbiology 7: 817. https://doi.org/10.3389/fmicb.2016.00817

Bai, J., Hu, Y. and Bruner, D.W., 2019. Composition of gut microbiota and its association with body mass index and lifestyle factors in a cohort of 7-18 years old children from the American Gut Project. Pediatric Obesity 14: e12480. https://doi.org/10.1111/ijpo.12480

Baños, A., García, J.D., Núñez, C., Mut-Salud, N., Ananou, S., MartínezBueno, M., Maqueda, M., and Valdivia E., 2019. Subchronic toxicity study in BALBc mice of enterocin AS-48, an anti-microbial peptide produced by Enterococcus faecalis UGRA10. Food Chemical Toxicology 132: 110667. https://doi.org/10.1016/j.fct.2019.110667

Barlow, G.M., Yu, A. and Mathur, R., 2015. Role of the gut microbiome in obesity and diabetes mellitus. Nutrition in Clinical Practice 30: 787-797. https://doi.org/10.1177/0884533615609896

Belguesmia, Y., Leclère, V., Duban, M., Auclair, E. and Drider, D., 2017. Draft genome sequence of Enterococcus faecalis DD14, a bacteriocinogenic lactic acid bacterium with anti-Clostridium activity. Genome Announcements 5. https://doi.org/10.1128/ genomeA.00695-17

Bradford, M.M., 1976. A rapid and sensitive method for the quantitation of microgram quantities of protein utilizing the principle of proteindye binding. Analytical Biochemistry 72: 248-254. https://doi. org/10.1006/abio.1976.9999 
Caly, D.L., Chevalier, M., Flahaut, C., Cudennec, B., Al Atya, A.K., Chataigné, G., D’Inca, R., Auclair, E. and Drider, D., 2017. The safe enterocin DD14 is a leaderless two-peptide bacteriocin with anti-Clostridium perfringens activity. International Journal of Antimicrobial Agents 49: 282-289. https://doi.org/10.1016/j. ijantimicag.2016.11.016

CA-SFM, 2019. CASFM/EUCAST 2019. Société Française de Microbiologie. https://www.sfm-microbiologie.org/2019/01/07/ casfm-eucast-2019/.

Chen, H. and Hoover, D.G., 2003. Bacteriocins and their food applications. Comprehensive Reviews in Food Science and Food Safety 2: 82-100. https://doi.org/10.1111/j.1541-4337.2003.tb00016.x

Cotter, P.D., Ross, R.P. and Hill, C., 2013. Bacteriocins - a viable alternative to antibiotics? Nature Reviews Microbiology 11: 95105. https://doi.org/10.1038/nrmicro2937

Dabard, J., Bridonneau, C., Phillipe, C., Anglade, P., Molle, D., Nardi, M., Ladiré, M., Girardin, H., Marcille, F., Gomez, A. and Fons, M., 2001. Ruminococcin A, a new lantibiotic produced by a Ruminococcus gnavus strain isolated from human feces. Applied and Environmental Microbiology 67: 4111-4118. https://doi.org/10.1128/ AEM.67.9.4111-4118.2001

De Almeida Vaucher, R., De Campos Velho Gewehr, C., Folmer Correa, A.P., Sant'Anna, V., Ferreira, J. and Brandelli, A., 2011. Evaluation of the immunogenicity and in vivo toxicity of the antimicrobial peptide P34. International Journal of Pharmaceutics 421: 94-98. https://doi.org/10.1016/j.ijpharm.2011.09.020

Dischinger, J., Basi Chipalu, S. and Bierbaum, G., 2014. Lantibiotics: promising candidates for future applications in health care. International Journal of Medical Microbiology 304: 51-62. https:// doi.org/10.1016/j.ijmm.2013.09.003

Drider, D. and Rebuffat, S., 2011. Prokaryotic antimicrobial peptides - from genes to applications. Springer, New York, NY, USA.

Dumitrescu, O., Dauwalder, O., Boisset, S., Reverdy, M.-É., Tristan, A. and Vandenesch, F., 2010. Résistance aux antibiotiques chez Staphylococcus aureus: les points-clés en 2010. Médecine/Sciences 26: 943-949. https://doi.org/10.1051/medsci/20102611943

Fernandez, B., Le Lay, C., Jean, J. and Fliss, I., 2013. Growth, acid production and bacteriocin production by probiotic candidates under simulated colonic conditions. Journal of Applied Microbiology 114: 877-885. https://doi.org/10.1111/jam.12081

Frazer, A.C., Sharratt, M. and Hickman, J.R., 1962. The biological effects of food additives. I. Nisin. Journal of the Science of Food and Agriculture 13: 32-42. https://doi.org/10.1002/jsfa.2740130106

Fuerst, J.A., 2013. The PVC superphylum: exceptions to the bacterial definition? Antonie Van Leeuwenhoek 104: 451-466. https://doi. org/10.1007/s10482-013-9986-1

Ghobrial, O., Derendorf, H. and Hillman, J.D., 2010. Human serum binding and its effect on the pharmacodynamics of the lantibiotic MU1140. European Journal of Pharmaceutical Sciences 41: 658-664. https://doi.org/10.1016/j.ejps.2010.09.005

Hartley, C.L., Clements, H.M. and Linton, K.B., 1978. Effects of cephalexin, erythromycin and clindamycin on the aerobic Gramnegative faecal flora in man. Journal of Medical Microbiology 11: 125-135. https://doi.org/10.1099/00222615-11-2-125
Huttenhower, C., Gevers, D., Knight, R., Abubucker, S., Badger, J.H., Chinwalla, A.T., Creasy, H.H., Earl, A.M., FitzGerald, M.G., Fulton, R.S., Giglio, M.G., Hallsworth-Pepin, K., Lobos, E.A., Madupu, R., Magrini, V., Martin, J.C., Mitreva, M., Muzny, D.M., Sodergren, E.J., Versalovic, J., Wollam, A.M., Worley, K.C., Wortman, J.R., Young, S.K., Zeng, Q., Aagaard, K.M., Abolude, O.O., Allen-Vercoe, E., Alm, E.J., Alvarado, L., Andersen, G.L., Anderson, S., Appelbaum, E., Arachchi, H.M., Armitage, G., Arze, C.A., Ayvaz, T., Baker, C.C., Begg, L., Belachew, T., Bhonagiri, V., Bihan, M., Blaser, M.J., Bloom, T., Bonazzi, V., Paul Brooks, J., Buck, G.A., Buhay, C.J., Busam, D.A., Campbell, J.L., Canon, S.R., Cantarel, B.L., Chain, P.S.G., Chen, I.-M.A., Chen, L., Chhibba, S., Chu, K., Ciulla, D.M., Clemente, J.C., Clifton, S.W., Conlan, S., Crabtree, J., Cutting, M.A., Davidovics, N.J., Davis, C.C., DeSantis, T.Z., Deal, C., Delehaunty, K.D., Dewhirst, F.E., Deych, E., Ding, Y., Dooling, D.J., Dugan, S.P., Michael Dunne, W., Scott Durkin, A., Edgar, R.C., Erlich, R.L., Farmer, C.N., Farrell, R.M., Faust, K., Feldgarden, M., Felix, V.M., Fisher, S., Fodor, A.A., Forney, L.J., Foster, L., Di Francesco, V., Friedman, J., Friedrich, D.C., Fronick, C.C., Fulton, L.L., Gao, H., Garcia, N., Giannoukos, G., Giblin, C., Giovanni, M.Y., Goldberg, J.M., Goll, J., Gonzalez, A., Griggs, A., Gujja, S., Kinder Haake, S., Haas, B.J., Hamilton, H.A., Harris, E.L., Hepburn, T.A., Herter, B., Hoffmann, D.E., Holder, M.E., Howarth, C., Huang, K.H., Huse, S.M., Izard, J., Jansson, J.K., Jiang, H., Jordan, C., Joshi, V., Katancik, J.A., Keitel, W.A., Kelley, S.T., Kells, C., King, N.B., Knights, D., Kong, H.H., Koren, O., Koren, S., Kota, K.C., Kovar, C.L., Kyrpides, N.C., La Rosa, P.S., Lee, S.L., Lemon, K.P., Lennon, N., Lewis, C.M., Lewis, L., Ley, R.E., Li, K., Liolios, K., Liu, B., Liu, Y., Lo, C.-C., Lozupone, C.A., Dwayne Lunsford, R., Madden, T., Mahurkar, A.A., Mannon, P.J., Mardis, E.R., Markowitz, V.M., Mavromatis, K., McCorrison, J.M., McDonald, D., McEwen, J., McGuire, A.L., McInnes, P., Mehta, T., Mihindukulasuriya, K.A., Miller, J.R., Minx, P.J., Newsham, I., Nusbaum, C., O’Laughlin, M., Orvis, J., Pagani, I., Palaniappan, K., Patel, S.M., Pearson, M., Peterson, J., Podar, M., Pohl, C., Pollard, K.S., Pop, M., Priest, M.E., Proctor, L.M., Qin, X., Raes, J., Ravel, J., Reid, J.G., Rho, M., Rhodes, R., Riehle, K.P., Rivera, M.C., Rodriguez-Mueller, B., Rogers, Y.-H., Ross, M.C., Russ, C., Sanka, R.K., Sankar, P., Fah Sathirapongsasuti, J., Schloss, J.A., Schloss, P.D., Schmidt, T.M., Scholz, M., Schriml, L., Schubert, A.M., Segata, N., Segre, J.A., Shannon, W.D., Sharp, R.R., Sharpton, T.J., Shenoy, N., Sheth, N.U., Simone, G.A., Singh, I., Smillie, C.S., Sobel, J.D., Sommer, D.D., Spicer, P., Sutton, G.G., Sykes, S.M., Tabbaa, D.G., Thiagarajan, M., Tomlinson, C.M., Torralba, M., Treangen, T.J., Truty, R.M., Vishnivetskaya, T.A., Walker, J., Wang, L., Wang, Z., Ward, D.V., Warren, W., Watson, M.A., Wellington, C., Wetterstrand, K.A., White, J.R., Wilczek-Boney, K., Wu, Y., Wylie, K.M., Wylie, T., Yandava, C., Ye, L., Ye, Y., Yooseph, S., Youmans, B.P., Zhang, L., Zhou, Y., Zhu, Y., Zoloth, L., Zucker, J.D., Birren, B.W., Gibbs, R.A., Highlander, S.K., Methé, B.A., Nelson, K.E., Petrosino, J.F., Weinstock, G.M., Wilson, R.K. and White, O. and the Human Microbiome Project Consortium, 2012. Structure, function and diversity of the healthy human microbiome. Nature 486: 207-214. https://doi.org/10.1038/nature11234. 
Ignacio, A., Fernandes, M.R., Rodrigues, V.A.A., Groppo, F.C., Cardoso, A.L., Avila-Campos, M.J. and Nakano, V., 2016. Correlation between body mass index and faecal microbiota from children. Clinical Microbiology and Infection 22: 258.e1-8. https://doi.org/10.1016/j. cmi.2015.10.031

Ketaren, N.B., Marlida, Y., Arnim, A., Yuherman, Y. and Rusmarilin, H., 2016. Toxicity test pediocin N6 powder produced from isolates Pediococcus pentosaceus strain N6 on white mice. Journal of Food and Pharmaceutical Sciences 4(1).

Kheadr, E., Zihler, A., Dabour, N., Lacroix, C., Le Blay, G. and Fliss, I., 2010. Study of the physicochemical and biological stability of pediocin PA-1 in the upper gastrointestinal tract conditions using a dynamic in vitro model. Journal of Applied Microbiology 109: 54-64. https://doi.org/10.1111/j.1365-2672.2009.04644.x

Köck, R., Becker, K., Cookson, B., Gemert-Pijnen, J.E. van, Harbarth, S., Kluytmans, J., Mielke, M., Peters, G., Skov, R.L., Struelens, M.J., Tacconelli, E., Torné, A.N., Witte, W. and Friedrich, A.W., 2010. Methicillin-resistant Staphylococcus aureus (MRSA): burden of disease and control challenges in Europe. Eurosurveillance 15: 19688. https://doi.org/10.2807/ese.15.41.19688-en

Kumar, V. and Tiwari, S.K., 2017. Halocin HA1: An archaeocin produced by the haloarchaeon Haloferax larsenii HA1. Process Biochemistry 61: 202-208. https://doi.org/10.1016/j.procbio.2017.06.010

Lagier, J.C., Million, M., Hugon, P., Armougom, F. and Raoult, D., 2012. Human gut microbiota: Repertoire and variations. Frontiers in Cellular and Infection Microbiology 2: 136. https://doi.org/10.3389/ fcimb.2012.00136

Lange, K., Buerger, M., Stallmach, A. and Bruns, T., 2016. Effects of antibiotics on gut microbiota. Digestive Diseases 34: 260-268. https://doi.org/10.1159/000443360

Langgartner, D., Peterlik, D., Foertsch, S., Füchsl, A.M., Brokmann, P., Flor, P.J., Shen, Z., Fox, J.G., Uschold-Schmidt, N., Lowry, C.A. and Reber, S.O., 2017. Individual differences in stress vulnerability: the role of gut pathobionts in stress-induced colitis. Brain, Behavior, and Immunity 64: 23-32. https://doi.org/10.1016/j.bbi.2016.12.019

Lee, A.S., de Lencastre, H., Garau, J., Kluytmans, J., MalhotraKumar, S., Peschel, A. and Harbarth, S., 2018. Methicillin-resistant Staphylococcus aureus. Nature Reviews Disease Primers 4: 18033. https://doi.org/10.1038/nrdp.2018.33

Lei, J., Sun, L., Huang, S., Zhu, C., Li, P., He, J., Mackey, V., Coy, D.H. and He, Q., 2019. The antimicrobial peptides and their potential clinical applications. American Journal of Translational Research 11: 3919-3931.

Ley, R.E., Bäckhed, F., Turnbaugh, P., Lozupone, C.A., Knight, R.D. and Gordon, J.I., 2005. Obesity alters gut microbial ecology. Proceedings of the National Academy of Sciences of the USA 102: 11070-11075. https://doi.org/10.1073/pnas.0504.978102

Ling, L.L., Schneider, T., Peoples, A.J., Spoering, A.L., Engels, I., Conlon, B.P., Mueller, A., Schäberle, T.F., Hughes, D.E., Epstein, S., Jones, M., Lazarides, L., Steadman, V.A., Cohen, D.R., Felix, C.R., Fetterman, K.A., Millett, W.P., Nitti, A.G., Zullo, A.M., Chen, C. and Lewis, K., 2015. A new antibiotic kills pathogens without detectable resistance. Nature 517: 455-459. https://doi.org/10.1038/ nature14098
Lussier, G., 1989. Histologie et histochimie. In: Payment, P. and Trudel, M. (eds.) Manuel de Techniques Virologiques. Presse de Université du Quebec, Sillery, Canada, pp. 63-179.

Maharshak, N., Packey, C.D., Ellermann, M., Manick, S., Siddle, J.P., Huh, E.Y., Plevy, S., Sartor, R.B. and Carroll, I.M., 2013. Altered enteric microbiota ecology in interleukin 10-deficient mice during development and progression of intestinal inflammation. Gut Microbes 4: 316-324. https://doi.org/10.4161/gmic.25486

Malachowa, N. and DeLeo, F.R., 2010. Mobile genetic elements of Staphylococcus aureus. Cellular and Molecular Life Sciences 67: 3057-3071. https://doi.org/10.1007/s00018-010-0389-4

Meade, E., Slattery, M.A. and Garvey, M., 2020. Bacteriocins, potent antimicrobial peptides and the fight against multi drug resistant species: resistance is futile? Antibiotics 9: 32. https://doi. org/10.3390/antibiotics9010032

Mishra, B., Reiling, S., Zarena, D. and Wang, G., 2017. Host defense antimicrobial peptides as antibiotics: design and application strategies. Current Opinion in Chemical Biology 38: 87-96. https:// doi.org/10.1016/j.cbpa.2017.03.014

Mizobuchi, S., Minami, J., Jin, F., Matsushita, O. and Okabe, A., 1994. Comparison of the virulence of methicillin-resistant and methicillinsensitive Staphylococcus aureus. Microbiology and Immunology 38: 599-605. https://doi.org/10.1111/j.1348-0421.1994.tb01829.x

O'Connor, P.M., Kuniyoshi, T.M., Oliveira, R.P., Hill, C., Ross, R.P. and Cotter, P.D., 2020. Antimicrobials for food and feed; a bacteriocin perspective. Current Opinion in Biotechnology 61: 160-167. https:// doi.org/10.1016/j.copbio.2019.12.023

Oksanen, J., Blanchet, F.G., Friendly, M., Kindt, R., Legendre, P., McGlinn, D., Minchin, P.R., O’Hara, R.B., Simpson, G.L., Solymos, P., Stevens, M.H.H., Szoecs, E. and Wagner, H., 2019. vegan: Community Ecology Package. Available at: https://cran.r-project. org/web/packages/vegan/index.html

Oksanen, J., Kindt, R. and Simpson, G.L., 2018. vegan3d: static and dynamic 3D plots for the 'vegan' package. Available at: https://rdrr. io/cran/vegan3d/

Ołdak, A. and Zielińska, D., 2017. Bacteriocins from lactic acid bacteria as an alternative to antibiotics. Postepy Higieny I Medycyny Doswiadczalnej 71: 328-338. https://doi. org/10.5604/01.3001.0010.3817

O’Neill, J., 2016. Tackling drug-resistant infections globally: final report and recommendations. Review on antimicrobial resistance. Wellcome Trust. Available at: https://wellcomecollection.org/works/ thvwsuba

Petersen, P.J., Labthavikul, P., Jones, C.H. and Bradford, P.A., 2006. In vitro antibacterial activities of tigecycline in combination with other antimicrobial agents determined by chequerboard and timekill kinetic analysis. Journal of Antimicrobial Chemotherapy 57: 573-576. https://doi.org/10.1093/jac/dki477

Quast, C., Pruesse, E., Yilmaz, P., Gerken, J., Schweer, T., Yarza, P., Peplies, J. and Glöckner, F.O., 2013. The SILVA ribosomal RNA gene database project: improved data processing and web-based tools. Nucleic Acids Research 41: D590-596. https://doi.org/10.1093/ nar/gks1219 
Renukuntla, J., Vadlapudi, A.D., Patel, A., Boddu, S.H.S. and Mitra, A.K., 2013. Approaches for enhancing oral bioavailability of peptides and proteins. International Journal of Pharmaceutics 447: 75-93. https://doi.org/10.1016/j.ijpharm.2013.02.030

Rizzatti, G., Lopetuso, L.R., Gibiino, G., Binda, C. and Gasbarrini, A., 2017. Proteobacteria: A Common Factor in Human Diseases. BioMed Research International 2017. https://doi.org/10.1155/2017/9351507

Rognes, T., Flouri, T., Nichols, B., Quince, C. and Mahé, F., 2016. VSEARCH: a versatile open source tool for metagenomics. PeerJ 4: e2584. https://doi.org/10.7717/peerj.2584

Ruppé, E., Burdet, C., Grall, N., de Lastours, V., Lescure, F.-X., Andremont, A. and Armand-Lefèvre, L., 2018. Impact of antibiotics on the intestinal microbiota needs to be re-defined to optimize antibiotic usage. Clinical Microbiology and Infection 24: 3-5. https:// doi.org/10.1016/j.cmi.2017.09.017

Sahoo, T.K., Jena, P.K., Prajapati, B., Gehlot, L., Patel, A.K. and Seshadri, S., 2017. In vivo assessment of immunogenicity and toxicity of the bacteriocin TSU4 in BALB/c mice. Probiotics and Antimicrobial Proteins 9: 345-354. https://doi.org/10.1007/s12602-016-9249-3

Schloss, P.D., Westcott, S.L., Ryabin, T., Hall, J.R., Hartmann, M., Hollister, E.B., Lesniewski, R.A., Oakley, B.B., Parks, D.H., Robinson, C.J., Sahl, J.W., Stres, B., Thallinger, G.G., Van Horn, D.J. and Weber, C.F., 2009. Introducing mothur: open-source, platform-independent, community-supported software for describing and comparing microbial communities. Applied and Environmental Microbiology 75: 7537-7541. https://doi.org/10.1128/AEM.01541-09

Schwiertz, A., Taras, D., Schäfer, K., Beijer, S., Bos, N.A., Donus, C. and Hardt, P.D., 2010. Microbiota and SCFA in lean and overweight healthy subjects. Obesity 18: 190-195. https://doi.org/10.1038/ oby. 2009.167

Seedorf, H., Griffin, N.W., Ridaura, V.K., Reyes, A., Cheng, J., Rey, F.E., Smith, M.I., Simon, G.M., Scheffrahn, R.H., Woebken, D., Spormann, A.M., Van Treuren, W., Ursell, L.K., Pirrung, M., Robbins-Pianka, A., Cantarel, B.L., Lombard, V., Henrissat, B., Knight, R. and Gordon, J.I., 2014. Bacteria from diverse habitats colonize and compete in the mouse gut. Cell 159: 253-266. https://doi.org/10.1016/j. cell.2014.09.008
Seo, M.-D., Won, H.-S., Kim, J.-H., Mishig-Ochir, T. and Lee, B.J., 2012. Antimicrobial peptides for therapeutic applications: a review. Molecules 17: 12276-12286. https://doi.org/10.3390/ molecules 171012276

Sobotta, J. and Welsch, U., 2000. Atlas d'histologie. Lavoisier. ed, Tech \& Doc, Paris, France.

Spencer, J.D., Schwaderer, A.L., Becknell, B., Watson, J. and Hains, D.S., 2014. The innate immune response during urinary tract infection and pyelonephritis. Pediatric Nephrology 29: 1139-1149. https:// doi.org/10.1007/s00467-013-2513-9

Sweeney, T.E. and Morton, J.M., 2013. The human gut microbiome: a review of the effect of obesity and surgically induced weight loss. JAMA Surgery 148: 563-569. https://doi.org/10.1001/ jamasurg. 2013.5

Turner, N.A., Sharma-Kuinkel, B.K., Maskarinec, S.A., Eichenberger, E.M., Shah, P.P., Carugati, M., Holland, T.L. and Fowler, V.G., 2019. Methicillin-resistant Staphylococcus aureus: an overview of basic and clinical research. Nature Reviews Microbiology 17: 203-218. https://doi.org/10.1038/s41579-018-0147-4

Vieco-Saiz, N., Belguesmia, Y., Raspoet, R., Auclair, E., Gancel, F., Kempf, I. and Drider, D., 2019. Benefits and inputs from lactic acid bacteria and their bacteriocins as alternatives to antibiotic growth promoters during food-animal production. Frontiers in Microbiology 10: 57. https://doi.org/10.3389/fmicb.2019.00057

Waite, D.W., Vanwonterghem, I., Rinke, C., Parks, D.H., Zhang, Y., Takai, K., Sievert, S.M., Simon, J., Campbell, B.J., Hanson, T.E., Woyke, T., Klotz, M.G. and Hugenholtz, P., 2017. Comparative genomic analysis of the class Epsilonproteobacteria and proposed reclassification to Epsilonbacteraeota (phyl. nov.). Frontiers in Microbiology 8: 682. https://doi.org/10.3389/fmicb.2017.00682 
